\section{INDUSTRIAL FATIGUE.}

THE Industrial Fatigue Research Board, which was recently appointed by the Department of Scientific and Industrial Research and the Medical Research Committee jointly, has quickly got into the swing of its labours. It has just issued two brief reports, and announces other more lengthy reports which are in preparation. In Report No. 2 Mrs. Ethel E. Osborne describes "The Output of Women Workers in Relation to Hours of Work in Shellmaking." The women were engaged in the operation of "ripping" or "part-off" on 6-in. shells, and their output was compared when they were on twelvehour and eight-hour shifts. The output of work achieved during each hour of actual work in the shorter shifts was 6.5 per cent. greater than in the longer shifts, but because of the improvement in timekeeping and the more efficient running of the machinery the production per hour of factory work was ${ }_{5} 5$ per cent. greater. Determinations of hourly output showed that during the last hour of the long shifts there was always a low output, whilst on the short shifts output was maintained throughout.

In Report No. 3 Col. C. S. Myers, a member of the Board, describes "A Study of Improved Methods in an Iron Foundry." Hitherto the American methods of time and motion study have gained very little acceptance in this country, and the enterprising managing director of the iron foundry investigated by Col. Myers is greatly to be congratulated on his initiative in applying the methods practically to the production of small iron castings. Although the hours of work were at the same time reduced from fifty-four to forty-eight per week, the men were able to increase their total output greatly, and they suffered less fatigue. The men were on piece rates, but they were paid on the novel, but wholly equitable, principle that the greater their production the greater their scale of pay per piece, or the rate of pay rose automatically with increase of total output. In that the overhead charges of a factory are usually almost the same whether the output of a worker be small or great, it is only fair that emplovers should adopt this system of payment, but it is absolutely exceptional for them to do so.

\section{MEAN SEA-LEVEL. ${ }^{1}$}

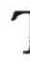

HE science of oceanography is slowly coming into its own, and it has advanced greatly in the last twenty years; but still, of those who think of it at all, many people know very little what it is. It is looked upon, often enough, as an easy, descriptive science, a small part of a simple, descriptive geography. But if this be true at all, it is a very small part of the truth; for the great problems of oceanography are physical problems, to be approached by mathematical methods, and soon involving us in difficult questions of hydrodynamics, and other difficulties besides. In the elementary task of the exploration of the sea Englishmen have taken a large, perhaps a lion's, share; in one special part of scientific hydrography, the theory of the tides, they have done a great deal, for such names as Lubbock, Whewell, Airy, Kelvin, and George Darwin come at once to our minds. But in other parts of the subject, and in recent times, we have done less; and the Scandinavian countries especially have done a great deal more. Bjerknes, Witting, Otto Pettersson, Sandström, Fridjof Nansen, Helland-Hansen. Madsen, and De la Cour are only a few names of men who, from Denmark to Finland, I Rolf Witting: "Hafivtan, Geoidvtan och Landhöjningen utmed Baltiska Hafvet och vid Nordsjön." Fennia 39, No. 5. (Helsingfors, s.98.)

NO. 2599, VOL. IO3] have studied the hydrographical phenomena of the Baltic or the wider problems of hydrography.

Among its most fundamental problems are those connected with the determination of mean sea-level-if we may so speak of something that has never yet been determined. There is scarcely a physical constant so freely spoken of $\mathrm{or}^{-}$so often used; every elevation in the world is referred to it, but no man knows what it is. Two or three generations ago a few observations of consecutive tides were supposed to be enough to ascertain it-a month was ample; but we have long known that the "constant" so determined is no constant at all, but is subject to complicated fluctuations, some regular and some, at first sight, erratic. This first approximation to "mean sea-level" has a very appreciable annual fluctuation, an "annual tide"; it alters from year to year; at any one locality these changes are apparently irregular, but they are found to tally with one another over large areas of coast; there are important differences of sea-level between one station and another; and there are slow changes of long period which again may be found common to large areas. Among the elementary difficulties of the problem is the fact that the annual change of level is much too great for a simple astronomical explanation-it is not a "solar tide"; and, that being excluded, we are thrown back on two hypotheses or sets of hypotheses, the one meteorological, the other based in one way or another upon movements of the earth's crust. A great deal has been written on the subject in recent years; we cannot attempt to review the whole question, but must be content to give an abstract of an important paper lately published by Prof. Rolf Witting, of Helsingfors, director of the Oceanographical Institute in that University.

The "level" of the sea, or, more generally speak. ing, the form of the surface of the sea, is a resultant of forces both extrinsic and intrinsic; that is to say (after we have eliminated by a sufficient number of observations the effect of the tides), we have to deal with the densities and currents of the sea itself, and with the winds and the atmospheric pressure acting upon its surface. It is plain that where the sea is less dense its surface will tend to stand at a higher level than where it is more so; this is an intrinsic phenomenon. As to the extrinsic forces, inasmuch as the winds are determined by the distribution of atmospheric pressure, the latter may be employed as our common indicator for both factors-that is to say, for the winds and for their effect upon the sea.

For the latter, or extrinsic, forces Prof. Witting gives us the following law or laws:--(I) Every baro metric distribution of any permanency produces a deformation of the surface of the sea. (2) The ascending slope so produced is not identical in direction with the barometric gradient, but deviates to its right-hand side, in the northern hemisphere. (3) The amount of slope is greater than that which would correspond with the hydrostatic pressure induced by the barometric distribution. (4) The amount of the deviation, and also the ratio between the amount of slope and the barometric gradient, are (to a first approximation) independent of the gradient, but largely affected by the shape of the basin and by the distribution of densities in its water-lavers.

From Fig. I we may judge, for a particular date, the relative directions of the barometric gradient and of the sloping surface of the Baltic isea.

In a celebrated observation (to which, by the way, Prof. Witting does not happen to refer) Sir James Ross found that, at a certain point within the Antarctic Ocean, a change of barometric pressure produced, to all intents and purposes, its precise hydrostatic equiva- 
lent in the level of the sea. But, whatever may have been the exact circumstances and conditions of that experiment, its result is very far from holding good within our narrow seas. According to Prof. Witting, both in the North Sea (on the average) and in the open basin of the Baltic the slope of the sea-surface is equivalent to a column of water about 35 times that of the barometric gradient measured in mercury; whereas, hydrostatically, the ratio should be only about 13.5 times, or in the simple ratio of the specific gravities of mercury and water; in still narrower areas, as in the gateways of the Baltic, the ratio may be much greater, amounting to as much as roo times. In the open basins the direction of the water-slope deviates from that of the barometric gradient by about $55^{\circ}$; and this value is again exceeded in the narrower channels. In other words, then, we find that in the opener basins the disturbance of the sealevel is nearly three times as great as the direct hydrostatic effect due to atmospheric pressure, which is as

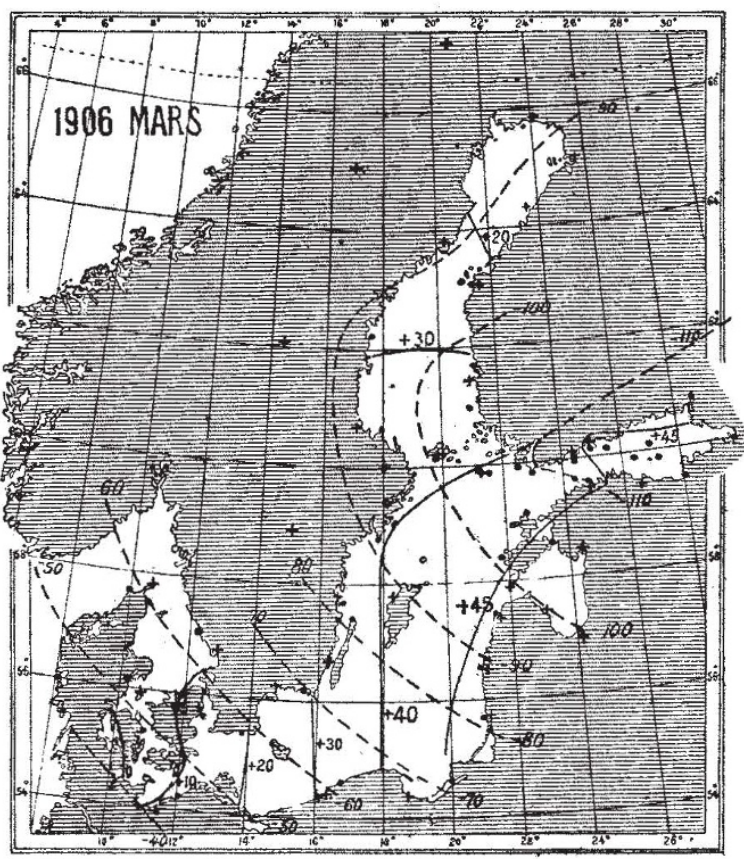

Ftg. 1.-Sea-level and pressure-distribution in March, 1906; represented by isanomalies from the means for the whole period 1898-19t2. Thick lines, sea-level in half-centimetres; broken lines, barometric pressure in tenth-millimetres.

much as to say that the dynamical effect of the wind must account for well-nigh two-thirds of the total effect produced. Moreover, in these waters the current produced by the wind deviates by about $20^{\circ}$ to the right of the direction of the wind itself; and the current thus moves sideways up the slope, about $45^{\circ}$ to the right of its uphill direction, which is an oceanographical paradex.

In the gateways of the Baltic these external forces by no means fully explain the phenomena which occur. We may calculate the amount of water which escapes from the Baltic, on an average, month by month; and, proportional to these amounts, we then discover residual deviations of slope in the water-levels. Within its gates the Baltic may be regarded as a basin the levels of which (except for perturbations at the mouths of rivers) are mainly determined by the barometric field. But the gateways themselves constitute a sluice, damming up the waters within; and in this NO. 2599 , VOL. IO3] region the height of the dam will depend not only on the atmospheric pressure, but also on the quantity of water which passes over into the North Sea, the level of which varies according to its local conditions and to more distant phenomena in the ocean. In a general way, the peculiarities of the narrow entrances to the Baltic are not difficult to comprehend.

But let us return to the internal forces, or, practically speaking, to the distribution of densities in the sea. We have here a direct cause of variation of surface-level, giving us, as it were, a theoretic or ideal sea-level at any particular place, largely affected in actual fact by extrinsic forces wrich move and heap up the waters. Now, we began by saying that mean sea-level, properly so-called, is a constant as yet undetermined. But, nevertheless, we know a very great deal more about it than we did even a few years ago, and can give a very fair approximation to it in a considerable number of localities. Even at Dundee or Aberdeen mean sea-level is a very different thing from

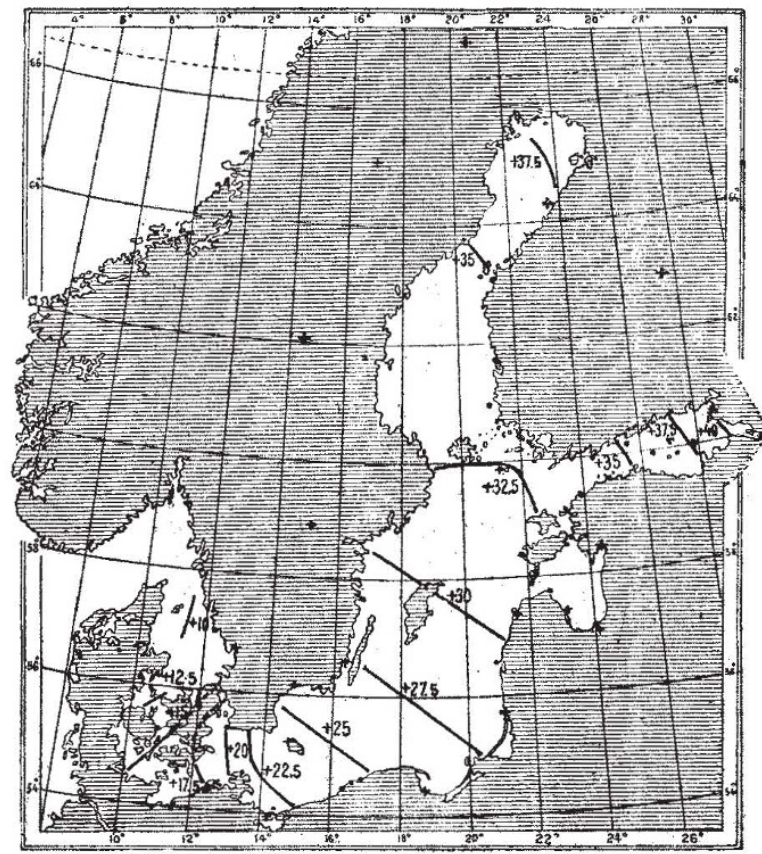

FIG. 2.-Mean sea-level, calculated values; referred (in centimetre-units) to a geoidic surface touching the North Sea in the middle of its northern part.

that mark at Liverpool from which all our Ordnance levels are reckoned, and, which (though by a happy accident it is not far from the truth) we all know to be a purely empirical or conventional datum. Now, as Prof. Witting argues, we do already know enough about this subject to be able to define, with a fair amount of accuracy, a "zero-pressure level" in the sea at a point where no movements are caused by the distribution of densities; to be more specific, we may choose a point somewhere towards the middle of the northern part of the North Sea, describe a geoidic surface touching it, and call that (to the best of our present knowledge) our datum level. Proceeding outwards from this zero point, we may calculate the hydrodynamical part of the slope due to the distribution of densities; and again we may calculate, and superadd to this, the slope due to barometric pressures, either for some particular epoch or in average values corresponding with long-period barometric means. In Fig. 2 Prof. Witting shows, after this manner, the 
calculated or hypothetic values of mean sea-level over the Baltic area, expressed in terms of deviation (or as isanomalies) from the geoidic surface defined above. It will be seen that these isanomalies are of an order of magnitude far beyond any probable errors in the determination of our base.

The next step, to be immediately taken, is to compare these calculated results with the observed results obtained by actual survey on land, with the most modern nivellements de précision achieved by the national Surveys. On this subject Prof. Witting has much to say, and he succeeds in showing that the two sets of results, the calculated and the observed, are wonderfully congruent. For example (and one example must suffice), Prof. Witting arrives by calculation at an estimated mean difference of sea-level between Marienleuchte, on the North Sea, and Arkona and Memel, in the Baltic, amounting respectively to +9.8 and $+x 7$ centimetres. The German Präcisionsnivellierung gives observed values of $\mathrm{I}$ I and $\mathrm{I} 7.6$ centi-

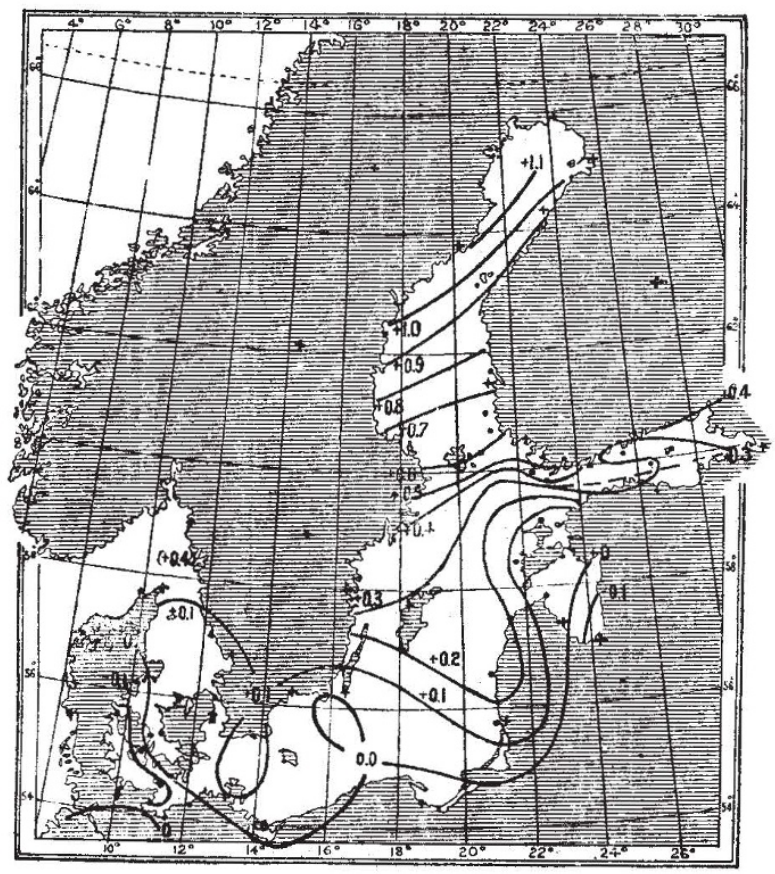

Fig. 3. - The mean rate of elevation of the land during the period $1898-19$ in centimetrs $S$ per annum.

metres. As good, or even better, agreement is shown between stations in the Baltic and Amsterdam, making use of the Dutch as well as the German levellings. In short, Prof. Witting has good right to boast that this part of oceanography has become an exact science, and that his "thalassographic levelling" bears favourable comparison with, and may even be used to check and to control, the most refined achievements of actual surveys on land.

The last remaining matter which presents itself is the question of long-period fluctuations of sea-level and the whole subject of secular elevation or depression of the land. Here we start at a disadvantage, from our great ignorance of the variations in level of the ocean itself. But we do know a good deal by observation, and we may learn a good deal more by Prof. Witting's method of calculation of the relative variations of level at various points of the coast. There is no fixed point which we can designate, but Prof. Witting shows that for about a century the NO. 2599 , VOL. IO3] coastal variations in the southern Baltic must have been very small. Suppose, then, that the coast from Wismar to Pillau has, on the whole, kept a constant level; we may then map out the relative changes over the rest of the Baltic area (as in Fig. 3) during the period of years (1898-1912) over which Prof. Witting's work extends. The result is striking enough; but the story does not $\in$ nd there. There are, on one hand, minor fluctuations within the area itself, and some of them are related to seismic phenomena; for instance, there was an interruption in the general upheaval about the time of the Scandinavian earthquake of 1904. On the other hand, the phenomena are directly related to those exhibited outside the Baltic area; and it may be said that, though certain minor differences exist-for instance, in Holland-it is clear enough that the Fennoscandian upheaval is only part of a larger movement of the earth's crust, which extends at least as far as the Netherlands and Scotland. From England the author has to regret that no observations were available.

With these recent scientific results regarding the elevation of the Baltic coasts Prof. Witting goes on to compare the earlier historic records and the prehistoric evidence, such as it is, which is available from archæology and from geology. He finds that for some centuries past the elevation of the Fiennoscandian lands has gone on at just about the same rate as to-day. The archæological evidence is more doubtful. It may be that the phenomenon has been approximately the same for some six thousand years; but it was possibly slower during and just after the Bronze age. Prof. Witting suggests-and this should interest the archæologists-that apparent contradictions would disappear if we might assume that the older relics are considerably older than Scandinavian archæologists are accustomed to consider them; and that, on the other hand, the Bronze age is not quite so old as it is commonly supposed to be. The more ancient phenomena are difficult to discuss, because a damming-up of the Baltic outlet may have produced results not to be distinguished from actual elevation of the lands within. But Prof. Witting believes that in the Littorina period there was certainly an interruption, and that probably just after the Glacial period there was an acceleration in the rate of elevation.

Prof. Witting brings a most interesting paper to a close with a strong plea for increased study of sealevels and all the related phenomena, and for such international co-operation as is obviously essential for a complete and systematic investigation of the whole subject.

D'ARcy W. Thompson.

\section{ENERGY DISTRIBUTION IN SPECTRA. ${ }^{1}$}

UR knowledge of the structure of very fine spectrum lines is now on a secure and nearly comprehensive basis, from the points of view of both theory and of experiment, and it is very' remarkable that so little is known of the distribution of energy in these lines, either in individual lines or as between the different lines contained in the spectrum of any atom. The analysis of the spectra of atoms, theoretically and in the laboratory, is now recognised as the most critical test to which any theory of atomic structure can be subjected, and we have recently had theories of the atom entirely based upon the wave-lengths of the radiations which they emit. A question of equal importance, to which $\mathbf{I}$ now wish to direct your attention, is the relative amounts of energy which the atom throws out in the form of radiation in the different

1 Discourse delivered at the Royal Institution on May 2 by Prof. J. W. Nicholson, F.R.S. 